\title{
Top-down synthesis strategies: Maximum noble-metal atom efficiency in catalytic materials
}

\author{
Yaxin Chen a, Zhiwei Huang a, Xiao Gu b, Zhen Ma a , Jianmin Chen a, Xingfu Tang a,c,* \\ a Institute of Atmospheric Sciences, Shanghai Key Laboratory of Atmospheric Particle Pollution \& Prevention (LAP3), Department of Environmental \\ Science \& Engineering, Fudan University, Shanghai 200433, China \\ b Department of Applied Physics, Chongqing University, Chongqing 401331, China \\ c Jiangsu Collaborative Innovation Center of Atmospheric Environment and Equipment Technology (CICAEET), Nanjing University of Information Science \\ \& Technology, Nanjing 210044, Jiangsu, China
}

\section{A R T I C L E I N F O}

\section{Article history:}

Received 29 November 2016

Accepted 30 December 2016

Published 5 September 2017

\section{Keywords:}

Top-down synthesis

Atomic dispersion

Catalytic active site

Electronic metal-support interaction

Formaldehyde oxidation

\begin{abstract}
A B S T R A C T
Top-down synthesis has been used to prepare catalytic materials with nanometer sizes, but fabricating atomically dispersed metal catalysts remains a challenge because surface single metal atoms are prone to aggregation or coalescence. A top-down strategy is used to synthesize atomically dispersed metal catalysts, based on supported Ag nanoparticles. The changes of the geometric and electronic structures of the Ag atoms during the top-down process are studied using the in situ synchrotron X-ray diffraction technique, ex situ X-ray absorption spectroscopy, and transmission electron microscopy. The experimental results, coupled with the density functional theory calculations, demonstrate that the electronic perturbation of the Ag frontier orbitals, induced by the Ag-0 interactions at the perimeter of the metal-support interface, is the driving force of the top-down process. The top-down synthesis has two important functions: to increase the number of catalytic active sites and to facilitate the study of complex reaction mechanisms (e.g., formaldehyde oxidation) by developing single-site model catalysts.
\end{abstract}

(C) 2017, Dalian Institute of Chemical Physics, Chinese Academy of Sciences. Published by Elsevier B.V. All rights reserved.

\section{Introduction}

Since the introduction of the concept of catalytically active sites (CASs) by Taylor in 1925 [1], great efforts have been devoted to identifying CASs to fully understand the intrinsic mechanisms of catalytic reactions and to improve existing catalysts or design improved catalysts [2-4]. However, accurate identification of CASs remains challenging, especially for supported metal particle/cluster catalysts, owing to the so-called intrinsic "metal effects" such as electronic quantum size effect [5-7] and structure sensitivity [8,9]. In fact, late transition met- al particles with small sizes have higher lying $d$-band/orbital centers (which play a crucial role in determining the catalytic activity [10]) compared with those having larger sizes [9]. Metal atoms at different local environments (e.g., at steps, edges, kinks, and corners) often have different electronic states [9], thus resulting in a different catalytic activity. In particular, the identification of the CASs of supported metal particle/cluster catalysts has led to much controversy, even under similar experimental conditions such as in the same reactions and with the same catalysts $[11,12]$. Thus, a complete elimination of the intrinsic metal effects is extremely difficult and even impossible

\footnotetext{
* Corresponding author. Tel: +86-21-65642997; Fax: +86-21-65643597; E-mai: tangxf@fudan.edu.cn.

This work was supported by the National Natural Science Foundation of China (21477023), and the Science and Technology Commission of Shanghai Municipality (14JC1400400).

DOI: 10.1016/S1872-2067(17)62778-5 | http://www.sciencedirect.com/science/journal/18722067 | Chin. J. Catal., Vol. 38, No. 9, September 2017
} 
for supported metal particle/cluster catalysts.

The above-mentioned issue can be solved if a uniform single-site heterogeneous catalyst with surface single metal atoms as active sites can be developed. However, it is tremendously difficult to synthesize such an atomically dispersed metal catalyst (ADMC) as metal atoms are often prone to sintering by the Ostwald ripening process during catalyst preparation and catalytic reactions $[13,14]$. Despite these difficulties, it is still feasible to synthesize ADMCs, depending on the nature of the supports. Kwak et al. [15] reported that platinum atoms bind to unsaturated coordinate $\mathrm{Al}^{3+}$ sites on the surface of the support by a binding-driven method to achieve an ADMC. Another ADMC involving platinum atoms that are anchored at electronic defects of iron oxide surfaces has also been synthesized [16]. However, a distinct drawback of these catalysts is the aggregation of metal atoms, especially when the metal loading is over 1 $\mathrm{wt} \%[15,16]$, which leads to a loss of activity or selectivity.

A so-called top-down synthesis strategy is one of the most efficient methods to synthesize materials with nanometer sizes [17], even with an atomically dispersed state [18,19]. In principle, the top-down method is feasible for the fabrication of an ADMC by controlling metal-support interactions such as the adhesion energy of metal atoms to the surfaces of the support $[20,21]$. Experimentally, we have used this method to synthesize an ADMC from Ag nanoparticles (NPs) through a simple thermal diffusion process $[18,19]$. In this article, we focused on the top-down synthesis process of the transformation from Ag NPs to single Ag sites with the assistance of the surface of the support. The top-down process is characterized by using in situ synchrotron X-ray diffraction (SXRD) and ex situ X-ray absorption spectroscopy. The geometric and electronic structures of the metal atoms during this process are thoroughly studied to correlate with the catalytic performance in the complete oxidation of formaldehyde (HCHO).

\section{Experimental}

\subsection{Materials preparation}

The synthesis of hollandite manganese oxide (HMO) NPs has previously been described [22,23]. Briefly, two solutions were first prepared: one aqueous solution $(170 \mathrm{~mL})$ was prepared by dissolving $\mathrm{KMnO}_{4}(11.600 \mathrm{~g}), \mathrm{Na}_{2} \mathrm{MoO}_{4}$ (1.228 g), $\mathrm{Na}_{3} \mathrm{VO}_{4} \cdot 12 \mathrm{H}_{2} \mathrm{O}$ (3.840 g), and $\mathrm{TiOSO}_{4} \cdot \mathrm{H}_{2} \mathrm{SO}_{4} \cdot 8 \mathrm{H}_{2} \mathrm{O}$ (1.536 g) in water; the other aqueous solution $(80 \mathrm{~mL})$ was prepared by dissolving $\mathrm{MnSO}_{4} \cdot \mathrm{H}_{2} \mathrm{O}(17.600 \mathrm{~g})$ and $\mathrm{FeSO}_{4} \cdot 7 \mathrm{H}_{2} \mathrm{O}(2.432 \mathrm{~g})$ in water. The former solution was added drop-wise to the latter to obtain a brown slurry, which was subsequently refluxed at 100 ${ }^{\circ} \mathrm{C}$ for $24 \mathrm{~h}$. The resulting solid was washed with de-ionized water, filtered, dried at $110{ }^{\circ} \mathrm{C}$ for $12 \mathrm{~h}$, and calcined at $400{ }^{\circ} \mathrm{C}$ for $4 \mathrm{~h}$.

A surface-anchored single-atom $\mathrm{Ag}$ catalyst $\left(\mathrm{Ag}_{1} / \mathrm{HMO}\right)$ was prepared by the thermal surface-mediated diffusion method of the corresponding supported Ag NP catalyst ( $\left.\mathrm{Ag}_{\mathrm{NP}} / \mathrm{HMO}\right)$. In brief, an aqueous ammonia solution (25 wt\%) was slowly added to an $\mathrm{AgNO}_{3}$ solution ( $30 \mathrm{~mL}$, containing $0.315 \mathrm{~g}$ of $\mathrm{AgNO}_{3}$ ) under stirring until the solution became transparent. Both the transparent solution and a $\mathrm{H}_{2} \mathrm{O}_{2}$ solution ( $30 \mathrm{wt} \%, 90 \mathrm{~mL}$ ) were simultaneously added to another aqueous suspension $(80 \mathrm{~mL})$ containing HMO (2.000 g) under stirring at $0{ }^{\circ} \mathrm{C}$ for $0.5 \mathrm{~h}$. The final suspension was filtered, washed with de-ionized water, and dried at $80^{\circ} \mathrm{C}$ for $12 \mathrm{~h}$ to obtain $\mathrm{Ag}_{\mathrm{NP}} / \mathrm{HMO}$. $\mathrm{Ag}_{\mathrm{NP}} / \mathrm{HMO}$ was annealed at 350 or $400{ }^{\circ} \mathrm{C}$ (as specified in the text) for $4 \mathrm{~h}$ to obtain $\mathrm{Ag}_{1} / \mathrm{HMO}$. The referential samples (Ag/HMO-ref and HMO-ref) were synthesized according to a previous report [18].

\subsection{Materials characterization}

The synchrotron X-ray diffraction (SXRD) patterns were obtained at the BL14B Beamline of the Shanghai Synchrotron Radiation Facility (SSRF) at a wavelength of $0.12398 \mathrm{~nm}$. The beam was monochromatized using $\mathrm{Si}$ (111), and a Rh/Si mirror was used for the beam focusing to a size of approximately 0.5 $\mathrm{mm} \times 0.5 \mathrm{~mm}$.

High-resolution transmission electron microscopy (HRTEM) images were obtained with a JEOL JEM-2100F field-emission transmission electron microscope operating at an accelerating voltage of $200 \mathrm{kV}$ and equipped with an ultra-high-resolution polepiece that provides a point-resolution better than $0.19 \mathrm{~nm}$. Fine powders of the materials were dispersed in ethanol, sonicated, sprayed on a carbon coated copper grid, and then allowed to air-dry for imaging.

XAS covers the X-ray absorption near-edge structure (XANES) spectra and extended X-ray absorption fine structure (EXAFS) spectra, which were recorded at the Ag $K$-edge using the BL14W Beamline of the SSRF with an electron beam energy of $3.5 \mathrm{GeV}$ and a ring current of 200-300 mA. Data were collected with a fixed exit monochromator using two flat $\mathrm{Si}(311)$ crystals. The XANES spectra were acquired at an energy step of $0.5 \mathrm{eV}$. The EXAFS spectra were collected in the transmission mode using ion chambers filled with $\mathrm{N}_{2}$. The raw data were analyzed using the IFEFFIT 1.2.11 software package.

$\mathrm{H}_{2}$ temperature-programmed reduction $\left(\mathrm{H}_{2}-\mathrm{TPR}\right)$ profiles were recorded using a ChemiSorb 2720 adsorption instrument. The sample $(\sim 20 \mathrm{mg})$ was reduced in a stream of $10 \%$ $\mathrm{H}_{2}-90 \% \mathrm{Ar}(50 \mathrm{~mL} / \mathrm{min})$ at a ramping rate of $10^{\circ} \mathrm{C} / \mathrm{min}$.

Prior to adsorption measurements, $\sim 15 \mathrm{mg}$ of the sample was pretreated in helium $(30 \mathrm{~mL} / \mathrm{min})$ at $120{ }^{\circ} \mathrm{C}$ for $30 \mathrm{~min}$. The sample was cooled to room temperature and CO was then pulsed from a calibrated on-line sampling loop $(18.60 \mu \mathrm{L})$ over the catalyst until the $\mathrm{CO}$ adsorption reached a saturation state. The amount of adsorbed CO on the surfaces of the catalyst was calculated by a dynamic method on an AutoChem II 2920 adsorption instrument.

\subsection{Catalytic evaluation}

The oxidation of HCHO was performed in a fixed-bed quartz reactor (i.d. $=8 \mathrm{~mm}$ ) under atmospheric pressure. A catalyst (25 mg, 40-60 mesh) was loaded for each run. Gaseous HCHO was generated by passing a $\mathrm{N}_{2}$ gas flow over paraformaldehyde in an incubator kept at $45{ }^{\circ} \mathrm{C}$, and then mixed with an $\mathrm{O}_{2}$ flow, leading to a feed gas containing $150 \mathrm{ppm}$ HCHO and $10.0 \mathrm{vol} \%$ $\mathrm{O}_{2}$, balanced by $\mathrm{N}_{2}$. The total flow rate was $100 \mathrm{~mL} / \mathrm{min}$. The 
effluents from the reactor were analyzed with an on-line Agilent 7890A gas chromatograph equipped with TCD and FID detectors. To compare the pre-exponential factors $(I)$, Arrhenius plots were obtained according to the catalytic activity of samples at $35-60{ }^{\circ} \mathrm{C}$ with the conversion of HCHO less than $20 \%$. The data were recorded up to the steady state for each run.

\subsection{Theoretical calculations}

All calculations in the current work were performed using the density functional theory (DFT) method implemented in the plane-wave basis Vienna Ab-initio Simulation Package (VASP) code [24]. The projector augmented wave potentials [25] and the approximation method of generalized gradient approximation [26] were used throughout the investigation. Sampling the Brillouin zone using a $(4 \times 4 \times 2)$ Monkhorst-Pack special $k$-point mesh yielded well-converged results. The energy cut off for the expansion of wave functions and potentials was $400.0 \mathrm{eV}$. The structures were relaxed using a conjugate gradient method with the convergence criteria for energy and forces set to $1 \times 10^{-5} \mathrm{eV}$ per supercell and $0.1 \mathrm{eV} / \mathrm{nm}$. A supercell of $\mathrm{Ag}_{2} \mathrm{Mn}_{8} \mathrm{O}_{16}$ or $\mathrm{Mn}_{8} \mathrm{O}_{16}$ units was constructed to simulate the terminals of $\mathrm{Ag}_{1} / \mathrm{HMO}$ or HMO. A vacuum region of $1.5 \mathrm{~nm}$ was used along the $z$ direction to avoid any spurious interactions among the periodical images.

\section{Results and discussion}

\subsection{A top-down synthesis}

Suitable metal-atom anchoring sites of supports are important for fabricating ADMCs by a top-down synthesis. Typically, HMO surfaces consist of terminated oxygen atom arrangements with desired sizes, which can serve as ideal sites for anchoring individual metal atoms [18,19]. HMO often grows along the [001] direction to form rods with a high aspect ratio owing to a lower surface energy of the (100) side-facets compared with the (001) top-facets (Fig. 1(a)) [27,28]. We modified the synthetic protocol to synthesize HMO NPs to increase the number of surface metal-atom anchoring sites by decreasing the aspect ratio of the HMO rods [22]. A typical HMO NP with a nanometer size of $\sim 4 \mathrm{~nm}$ is visualized in an HRTEM image (Fig. 1(b),(c)), and these HMO NPs have a higher specific surface area $\left(157 \mathrm{~m}^{2} / \mathrm{g}\right)$ than HMO nanorods $\left(46 \mathrm{~m}^{2} / \mathrm{g}\right)$ [18], thus increasing the number of surface anchoring sites.

A common method to achieve ADMCs is based on the fact that anchoring sites directly capture individual metal atoms from metal monomer compound precursors [15,16]. In this work, HMO NPs were used as a support to synthesize ADMCs. To synthesize $\mathrm{Ag}_{1} / \mathrm{HMO}$, Ag NPs with a truncated octahedron shape were initially supported on the HMO surfaces to get $\mathrm{Ag}_{\mathrm{NP}} / \mathrm{HMO}$ (Fig. 1(d)). The Ag NPs with $\sim 2 \mathrm{~nm}$ in height and $\sim 4$ $\mathrm{nm}$ in width were disintegrated into single $\mathrm{Ag}$ atoms which were then anchored on HMO surfaces by a thermal process (Fig. 1(e)) [18], indicating the presence of a large adhesion energy of Ag atoms to the HMO surfaces [20]. This is a typical
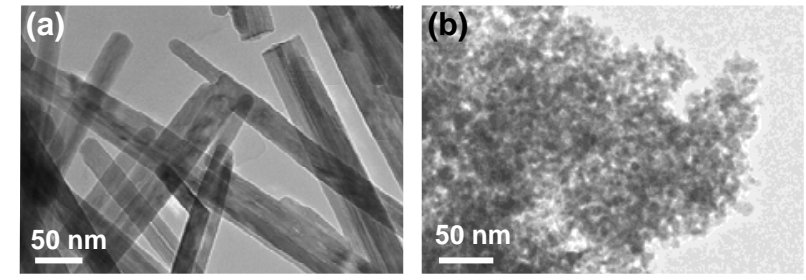

(c)
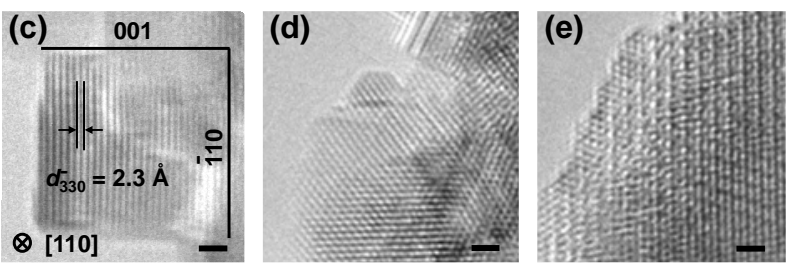

Fig. 1. TEM images of (a) HMO-ref, (b) HMO NPs and HRTEM images of (c) HMO NP, (d) a typical truncated Ag octahedron supported on HMO NP surface and (e) $\mathrm{Ag}_{1} / \mathrm{HMO}$.

top-down process, in which large metal particles/clusters tend to form single metal sites, unlike normal Ostwald ripening processes $[14,29]$.

\subsection{Direct observation of the top-down process}

In situ SXRD was used to investigate the transformation of supported Ag NPs to single Ag sites with the assistance of HMO NP surfaces. With an increase of the temperature, the diffraction intensity of Ag NPs became weaker and ultimately disappeared, indicating that Ag NPs gradually shrank and finally reached a highly dispersed state (Fig. 2(a)). For better visualization, a curve of the Ag(111) SXRD intensity as a function of temperature and its first derivative are shown in Fig. 2(b). When the temperature was lower than $150^{\circ} \mathrm{C}$, the $\mathrm{Ag}(111)$ intensity remained unchanged, indicating that the size of $\mathrm{Ag}$ NPs did not change below $150{ }^{\circ} \mathrm{C}$. When the temperature was higher than $150{ }^{\circ} \mathrm{C}$, the intensity became weaker, and the diffusing rate became faster with the increase of the temperature, reaching a maximum at $\sim 200{ }^{\circ} \mathrm{C}$. When the temperature was higher than $\sim 260{ }^{\circ} \mathrm{C}$, the $\mathrm{Ag}(111)$ reflection vanished, and the diffusing rate was stable, indicating that $\mathrm{Ag}$ finally reached a highly dispersed state.

To study the detailed top-down process, $\mathrm{Ag}_{\mathrm{NP}} / \mathrm{HMO}$ was annealed at different temperatures with a temperature-programmed procedure similar to that of the in situ SXRD experiment to give a series of Ag- $T$ samples ( $T=150,200$, or $350{ }^{\circ} \mathrm{C}$, and here, $T$ represents annealing temperature), and then ex situ EXAFS spectra were recorded to investigate the local environments of the Ag atoms of the samples. Fig. 3 shows Fourier transform (FT) amplitudes of the $\chi(R) k^{2}$-weighted EXAFS data at the Ag $K$-edge of the samples, and the structural parameters obtained by fitting the spectra with theoretical models are summarized in Table 1 [30]. The near neighbor Ag-Ag coordination shell appears in the FT spectrum of the Ag-150 sample with an average distance of $\sim 0.287 \mathrm{~nm}$ and a coordination number $(C N)$ of $\sim 8$, indicating the presence of metal Ag NPs, consistent with the in situ SXRD patterns (Fig. 2(a)). The FT amplitude of the EXAFS spectrum of the Ag-200 

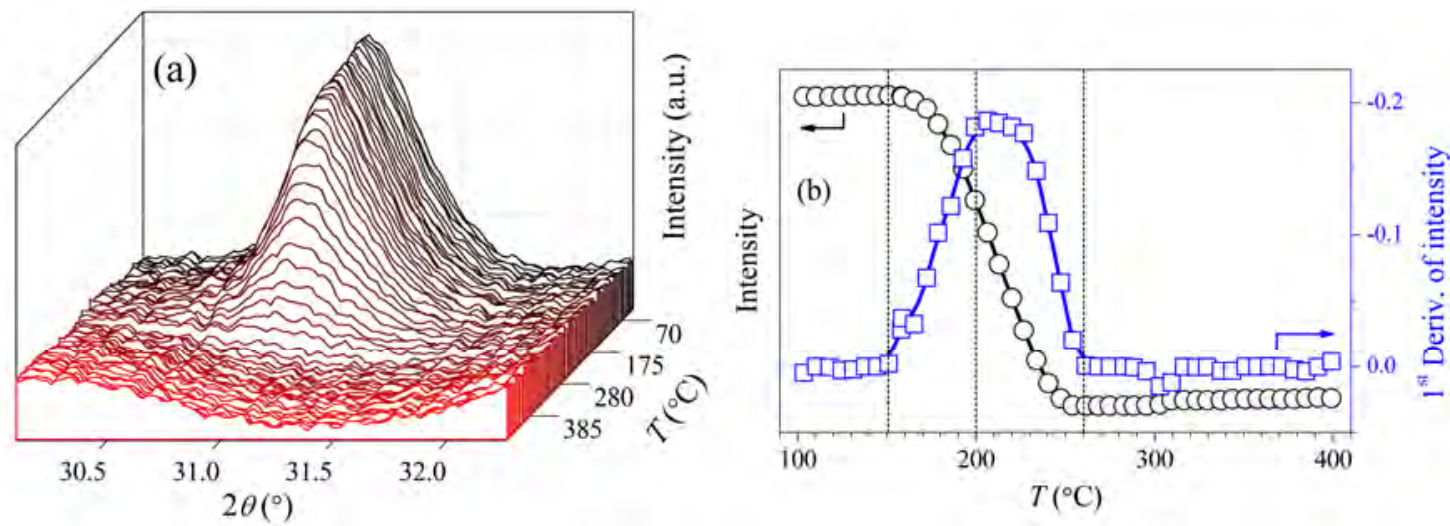

Fig. 2. (a) In situ SXRD patterns of $\mathrm{Ag}_{\mathrm{NP}} / \mathrm{HMO}$ as a function of temperature (the gradual change in color from black to red indicates the gradual increase of temperature); (b) The $\mathrm{Ag}(111)$ intensity (black circles) and the corresponding first derivative (blue squares) of the in situ SXRD patterns of $\mathrm{Ag}_{\mathrm{NP}} / \mathrm{HMO}$. The heating rate was $3.5^{\circ} \mathrm{C} / \mathrm{min}$.

sample at $0.28-0.30 \mathrm{~nm}$, which can be ascribed to the scattering between $\mathrm{Ag}$ atoms, is very weak, indicative of a very low average $C N$ of $\mathrm{Ag}$ atoms at this shell. The results of the fitting of the EXAFS spectra, giving an Ag-Ag $C N$ of 2.6, confirm this hypothesis (Table 1). In the FT EXAFS spectrum of the Ag-350 sample, the absence of the peak arising from Ag-Ag bonds indicates the formation of single Ag sites on the HMO surfaces [18], unlike the reported $\mathrm{Ag}_{1} / \mathrm{HMO}$-ref with tunnel $\mathrm{Ag}$ atoms (the FT XAFS spectrum of the $\mathrm{Ag}_{1} / \mathrm{HMO}$-ref is also shown in Fig. 3 for comparison) $[18,19]$. As shown in the FT spectrum of $\mathrm{Ag}_{1} / \mathrm{HMO}$ (Ag-350), the first shell can be attributed to two kinds of Ag-O bonds with an average bond length of $\sim 0.233 \mathrm{~nm}$ and $C N=4$ (Table 1), indicating that single Ag sites are on the four-fold

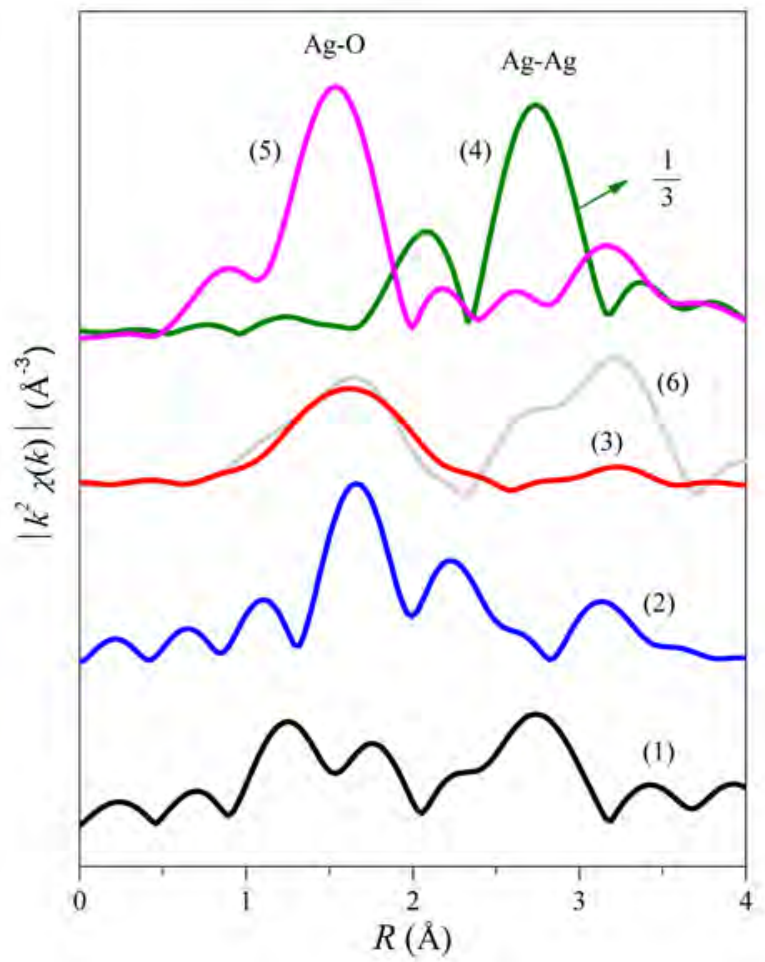

Fig. 3. $\chi(R) k^{2}$-weighted FT EXAFS spectra of the Ag-150 (1), Ag-200 (2), $\mathrm{Ag}-350$ (3), Ag foil (4), $\mathrm{Ag}_{2} \mathrm{O}$ (5), and $\mathrm{Ag}_{1} / \mathrm{HMO}-\mathrm{ref}(6)$. oxygen-terminated sites of the HMO surfaces [31]. Therefore, the combination of the in situ SXRD patterns and the ex situ EXAFS spectra evidence that Ag NPs have transformed into single Ag sites through the thermal diffusion process.

According to its first derivative of the in situ SXRD patterns above, we estimated the diffusion barrier $\left(E_{\mathrm{d}}\right)$ for the Ag atoms detached from Ag NPs using $E_{\mathrm{d}}=\ln \left(v_{0} / \gamma\right) k_{\mathrm{B}} T$, where $w, k_{\mathrm{B}}, T$ and $\gamma$ are the usual pre-factor (often taking $v_{0}=6 \times 10^{12}$ ) [32], the Boltzmann constant, the temperature in Kelvin $(\mathrm{K})$ and the rate relevant to a deposition rate, respectively. According to the in situ XRD (Fig. 2) and TEM data (Fig. 1(d)) of $\mathrm{Ag}_{\mathrm{NP}} / \mathrm{HMO}$, the average deposition rate of Ag NPs was $\sim 0.003 \mathrm{ML} / \mathrm{s}$. Therefore, we chose a typical value $\gamma=1 \mathrm{~s}^{-1}$ [32]. At $T=420 \mathrm{~K}\left(\sim 150{ }^{\circ} \mathrm{C}\right)$, the calculated $E_{\mathrm{d}}$ was $1.07 \mathrm{eV}$ for $\mathrm{Ag}$ atoms detached from $\mathrm{Ag}$ NPs. To investigate the stability of the single atom embedded on a HMO(100) surface, we carried out DFT calculations. The semi-tunnels of the HMO(100) surface provide perfect adsorption sites for single Ag atoms, that is, Ag atoms are embedded into the semi-tunnels surrounded by four oxygen atoms (the average Ag-O distance is $0.247 \mathrm{~nm}$ ). The calculated adsorption energy $\left(E_{\mathrm{ad}}\right)$ of $\mathrm{Ag}$ atoms on the four-fold oxygen-terminated sites of the $\mathrm{HMO}(100)$ surface is $-1.51 \mathrm{eV}$ with respect to bulk Ag. Here, $E_{\mathrm{ad}}=E_{\mathrm{s}_{-} \mathrm{Ag}}-E_{\mathrm{s}}-E_{\mathrm{Ag}}$, where $E_{\mathrm{s}_{-} \mathrm{Ag}}$ is the total energy of a

Table 1

EXAFS analysis results of the samples at the Ag $K$-edge a.

\begin{tabular}{lcrcccc}
\hline Sample & Shell & $N^{\mathrm{b}}$ & $R^{\mathrm{c}}(\mathrm{nm})$ & $\sigma^{2}$ & $\Delta E_{0} \mathrm{e}$ & $\mathrm{R}$-factor \\
\hline Ag-150 & Ag-O & 1.9 & $0.233(1)$ & $0.005(1)$ & +3.5 & 0.001 \\
& Ag-0 & 1.8 & $0.262(6)$ & $0.005(0)$ & -4.3 & 0.001 \\
& Ag-Ag & 8 & $0.286(9)$ & $0.040(3)$ & -3.2 & 0.001 \\
Ag-200 & Ag-0 & 3.7 & $0.233(1)$ & $0.005(1)$ & +1.0 & 0.001 \\
& Ag-O & 1.5 & $0.262(6)$ & $0.005(0)$ & -7.3 & 0.001 \\
& Ag-Ag & 2.6 & $0.286(8)$ & $0.066(1)$ & -2.9 & 0.001 \\
Ag-350 & Ag-O & 4 & $0.233(1)$ & $0.002(1)$ & -1.1 & 0.001 \\
& Ag-O & 2 & $0.262(6)$ & $0.004(5)$ & -7.4 & 0.001 \\
Ag foil & Ag-Ag & 12 & $0.289(1)$ & $0.033(5)$ & +2.2 & 0.001 \\
Ag 20 & Ag-0 & 2 & $0.203(7)$ & $0.016(1)$ & +2.3 & 0.001 \\
& Ag-Ag & 12 & $0.331(2)$ & $0.029(3)$ & +3.5 & 0.001 \\
\hline
\end{tabular}

a $R$-space fit, $\Delta k=0.17-0.81 \mathrm{~nm}^{-1}, \Delta r=0.12-0.39 \mathrm{~nm}^{\mathrm{b}} N$, coordination number; ${ }^{\mathrm{c}} R$, distance between absorber and backscatter atoms; ${ }^{\mathrm{d}} \sigma^{2}$, Debye-Waller factor; ${ }^{\mathrm{e}} \Delta E_{0}$, energy shift. 
single $\mathrm{Ag}$ atom adsorbed on the $\mathrm{HMO}(100)$ surface, $E_{\mathrm{s}}$ is the total energy of the bare HMO surface, and $E_{\mathrm{Ag}}$ is the total energy of the Ag bulk for each $\mathrm{Ag}$ atom. It is clear that a single $\mathrm{Ag}$ atom is energetically stable when embedded in a semi-tunnel of the HMO(100) surface. We also calculated the diffusion barrier for an embedded silver atom migrating from site to site in the semi-tunnels. As shown in Fig. 4, the barrier of such diffusion inside the semi-tunnels is quite small, that is, $\sim 0.18 \mathrm{eV}$. This indicates the facile dispersion of embedded single Ag atoms.

The stability of single metal atoms or metal NPs with relatively high melting points of the bulk metals, such as $\mathrm{Au}$ [33], Pt $[15,16,34,35]$, and $\mathrm{Rh}[36]$, has been well documented. Owing to the relatively low melting point of bulk $\mathrm{Ag}$, highly dispersed $\mathrm{Ag}$ atoms should be more mobile and prone to aggregation or coalescence. In fact, Ag particles with a sub-10 nm size are not thermally stable and often show liquid-like behavior [37]. Even though $\mathrm{Al}_{2} \mathrm{O}_{3}$ could provide anchoring sites for stabilizing single Pt atoms [15,34], Ag clusters, such as Ag trimers supported on $\mathrm{Al}_{2} \mathrm{O}_{3}$, are prone to sintering to form big particles, even at temperatures lower than $120^{\circ} \mathrm{C}$ [38]. Theoretically, single $\mathrm{Ag}$ atoms should be energetically more favorable to aggregate into large particles than Ag NPs/clusters. However, according to the HRTEM image (Fig. 1), the in situ SXRD patterns (Fig. 2) and the ex situ EXAFS spectra (Fig. 3), single Ag atoms anchored on the surface oxygen-terminated sites are extremely stable even at $>350^{\circ} \mathrm{C}$ under oxidizing conditions (Figs. $1-3$ ).

\subsection{Driving force of the top-down process}

Ag $K$-edge XANES was used to study the electronic states of $\mathrm{Ag}$ atoms of the Ag- $T$ samples during the top-down process together with two referential samples, $\mathrm{Ag}$ foil and $\mathrm{Ag}_{2} \mathrm{O}$. Fig. 5(a) shows the Ag $K$-edge XANES spectra of the samples. The edge positions for all the Ag- $T$ samples appear between those of the $\mathrm{Ag}$ foil and $\mathrm{Ag}_{2} \mathrm{O}$, indicating that the electronic states of $\mathrm{Ag}$ atoms of the $\mathrm{Ag}-\mathrm{T}$ samples are at a mediate state between the $\mathrm{Ag}$ foil and $\mathrm{Ag}_{2} \mathrm{O}$.

To investigate the subtle change of the electronic states of $\mathrm{Ag}$ atoms during the top-down process, we focused on the $1 \mathrm{~s} \rightarrow$ $5 p$ electron transition in the XANES spectra (the inset of Fig. 5(a)). The white-lines of the Ag- $T$ samples were more intense

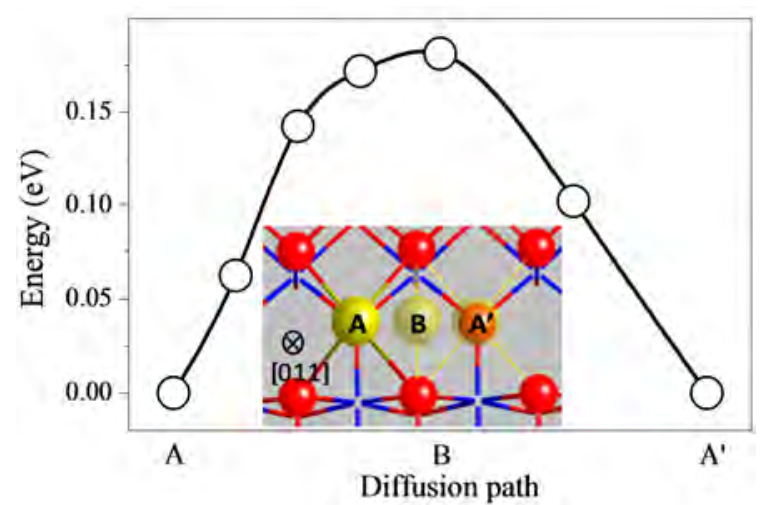

Fig. 4. Diffusion path of an Ag atom on the HMO surface. Inset: An atom model showing the diffusion path. Yellow, red, and blue balls represent $\mathrm{Ag}, \mathrm{O}$, and Mn, respectively. than that of the Ag foil, indicating a decrease in the electron density of Ag $5 p$ orbitals. The electron density of Ag $5 p$ orbitals might originate from the hybridization of the Ag frontier $d$-sp orbitals, especially with $02 p$ orbitals [19], although the Ag $5 p$ orbitals are unoccupied at the ground state of $\mathrm{Ag}$ atoms with a valence electron configuration of $4 d^{10} 5 s^{1} 5 p^{0}$. Similarly, the electron density of Ag $5 p$ orbitals becomes lower during the top-down process judging from the more and more intense $1 \mathrm{~s}$ $\rightarrow 5 p$ absorption edges from $\mathrm{Ag}_{\mathrm{NP}} / \mathrm{HMO}$ (Ag-150) to $\mathrm{Ag}_{1} / \mathrm{HMO}$ (Ag-350) during the top-down process.

Fig. 5(b) shows the differential X-ray absorption near-edge structure ( $\triangle \mathrm{XANES}$ ) spectra, which are highly sensitive and highly accurate for exploring the unoccupied states of $\mathrm{Ag} 4 \mathrm{~d}$ orbitals with respect to the spectrum of $\mathrm{Ag}_{2} \mathrm{O}$ [18,39]. A weak intensity in the $\triangle$ XANES spectrum of the Ag- $T$ samples can be ascribed to the $1 s \rightarrow 4 d$ electronic transition owing to the small $d-p$ hybridization of the Ag frontier orbitals [39-41]. The $\triangle$ XANES spectra of the Ag- $T$ samples show a pre-edge energy absorption shoulder in comparison with the XANES spectrum of $\mathrm{Ag}_{2} \mathrm{O}$ with an almost filled $d$ orbital configuration $\left(d^{10}\right)$ of $\mathrm{Ag}^{+}$ [42]. According to the absorption population at the pre-edge regime, the electron density of Ag $4 d$ orbitals of each Ag- $T$ sample is slightly lower than that of the Ag foil. The results are consistent with the fact that the smaller the size of Ag particles, the lower the electron density of the Ag $4 d$ orbitals, and the stronger the Ag-Ag bonds [43]. For the Ag-T samples, the electron density of the Ag $4 d$ orbitals gradually increases during the top-down process. Therefore, the results elucidate that when
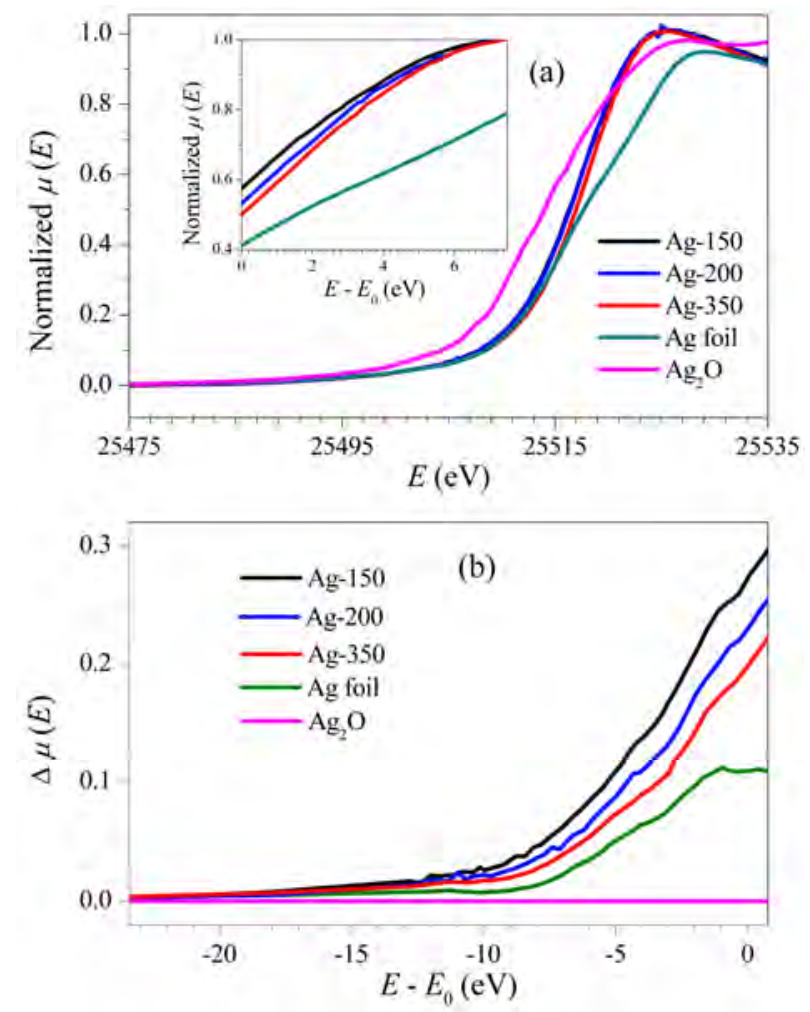

Fig. 5. (a) XANES spectra at the Ag $K$-edge of the samples; (b) $\triangle X A N E S$ spectra of the samples. $E$ is the absorption energy; $E_{0}$ is the absorption threshold energy. 
Ag NPs transform into individual surface Ag atoms anchored on the oxygen-terminated sites, Ag $5 p$ orbitals are relaxed and lose their partial charge because all $\mathrm{Ag}$ atoms are exposed on the surfaces, but Ag $4 d$ orbitals increase the electron density presumably because of the Ag-O interactions.

To investigate the change of the electron density of the Ag frontier orbitals, DFT calculations were conducted and the configurations of the surface Ag atoms and the electronic states are displayed in Fig. 6. The density of states (DOS) of single Ag atoms are remarkably different from those of bulk Ag, as explained by the interaction of Ag atoms with surface lattice oxygen atoms. According to the atom configuration of single Ag atoms, Ag orbital splitting occurs (Fig. 6), and DFT predicts the highest-lying $d_{z}^{2}$, the lowest-lying $d_{x y}$ orbital, and the $d_{x^{2}-y^{2}}$ and the doubly degenerate $d_{x z}$ and $d_{y z}$ orbitals. All Ag $4 d$ orbitals are shifted up after interacting with the surface oxygen atoms, and the Ag $4 d$ electron density obviously increases owing largely to the partial negative charge transferring from the $02 p_{z}$ orbital into the highest $\mathrm{Ag} 4 d_{z}^{2}$ orbital with partial depletion.

The above results provide strong evidence that the driving force of the top-down process is the interaction between $\mathrm{Ag}$ atoms and the surface oxygen atoms of the HMO. In detail, first, the surface atoms of Ag NPs spill out the $5 p$ electrons (with the possibility of also spilling out part of the $5 s$ electrons), which is favorable for weakening the Pauli repulsion with surface lattice oxygen atoms of $\mathrm{HMO}$, allowing a strong $\mathrm{Ag}-\mathrm{O}$ interaction to occur. Second, Ag atoms at the perimeter of the Ag-HMO interface strongly interact with surface oxygen atoms, allowing the electron density of the Ag $4 d$ orbitals to increase. Because of the almost full $\mathrm{Ag} 4 d$ shells, the increase in electrons in the $\mathrm{Ag} 4 d$ orbitals preferentially occupy the anti-bonding orbitals, which weakens Ag-Ag bonds, leading to the low energy barrier (1.07 $\mathrm{eV}$ ) for Ag atoms being detached from Ag NPs. Finally, the detached Ag atoms can diffuse on the HMO surface with relative ease owing to the low diffusion barrier $(0.18 \mathrm{eV})$, as predicted by the DFT calculations above. Therefore, the driving force of the top-down process can be attributed to the electronic perturbation of $\mathrm{Ag}$ frontier orbitals induced by $\mathrm{Ag}-\mathrm{O}$ interactions at the perimeter of the Ag-HMO interface [2,3,19].

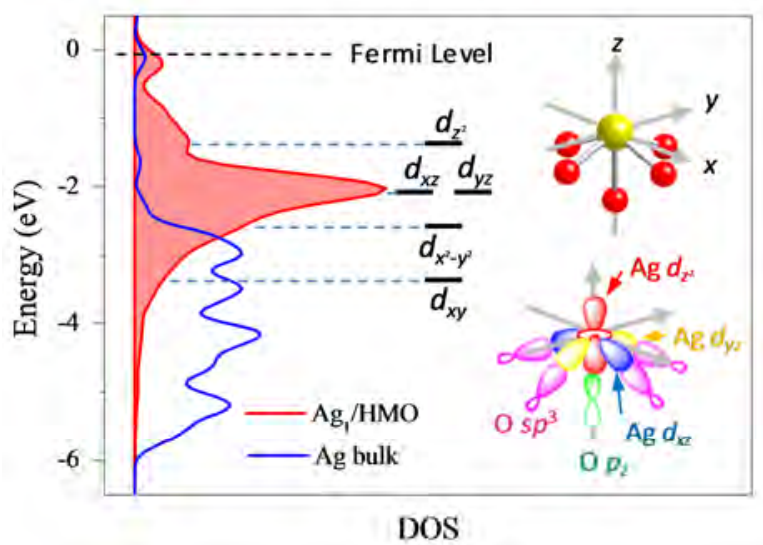

Fig. 6. DOS of the $\mathrm{Ag} 4 d$ orbitals and the $\mathrm{AgO}_{5}$ configuration together with the corresponding $d$ orbital spilling. Yellow and red balls represent Ag and 0 , respectively. Only halves of the $d_{x z}$ and $d_{y z}$ orbitals are drawn for clarity. $\mathrm{O}_{s p}{ }^{3}$ represents the $\mathrm{O}$ atom with $s p^{3}$ hybridization.

\subsection{Functions of the top-down synthesis}

The top-down synthesis has two important functions for catalysis research: (i) to increase the number of CASs through moving bulk metal atoms onto surfaces; (ii) to provide model single-site catalysts with uniform and ideal CASs, which are favorable for investigating reaction mechanisms.

We chose the HCHO oxidation reaction as an example to interpret the functions of the top-down synthesis because the number of exposed Ag atoms directly determines the reaction rate in low-temperature $\mathrm{HCHO}$ oxidation, and $\mathrm{HCHO}$ is a typical indoor and outdoor air pollutant [44] that contributes greatly to atmospheric particulate emissions [45]. As shown in Fig. 7 (a), the $\mathrm{HCHO}$ reaction rates at $80^{\circ} \mathrm{C}$ increased from $2.1 \times 10^{-7}$ $\mathrm{mol} /(\mathrm{g} \cdot \mathrm{s})$ to $5.5 \times 10^{-7} \mathrm{~mol} /(\mathrm{g} \cdot \mathrm{s})$, as the annealing temperature of $\mathrm{Ag}_{\mathrm{NP}} / \mathrm{HMO}$ increased from 150 to $300{ }^{\circ} \mathrm{C}$, respectively, and leveled off as the annealing temperature was further increased to $400{ }^{\circ} \mathrm{C}$. Under the same conditions, $\mathrm{HMO}$ is inactive in $\mathrm{HCHO}$ oxidation [31].

To elucidate the results above, the apparent activation energy $\left(E_{a}\right)$ and the $\Gamma$ of $\mathrm{HCHO}$ oxidation on the Ag- $T$ catalysts were calculated (Fig. 7(b)). The $E_{\mathrm{a}}$ of HCHO oxidation over Ag-150 (0.53 eV) was almost the same as that $(0.54 \mathrm{eV})$ of $\mathrm{Ag}-350$, and also similar to the reported $E_{\text {a values in HCHO ox- }}$ idation over other Ag-based catalysts [46]. However, the calculated $\Gamma$ for $\mathrm{Ag}_{1} / \mathrm{HMO}(\mathrm{Ag}-350)$ was $1.4 \times 10^{26}$ molecules $/(\mathrm{g} \cdot \mathrm{s})$, which is much higher than that of Ag-150 (4.5 $\times 10^{25}$ mole-
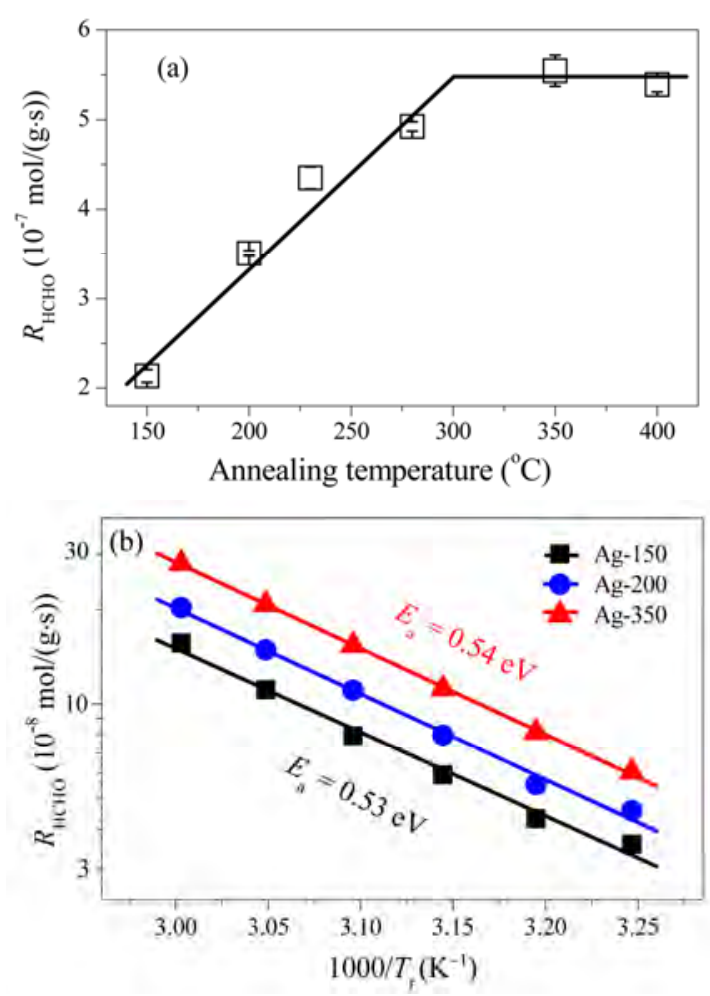

Fig. 7. (a) The reaction rates of $\mathrm{HCHO}\left(R_{\mathrm{HCHO}}\right)$ at $80^{\circ} \mathrm{C}$ over the catalysts at different annealing temperatures; (b) The Arrhenius plots for $R_{\mathrm{HCHO}}$ in the $\mathrm{HCHO}$ oxidations over the catalysts in a temperature $\left(T_{\mathrm{r}}\right)$ window of $35-60{ }^{\circ} \mathrm{C}$. 
cules/(g-s)) and Ag-200 (9.2 × $10^{25}$ molecules/(g·s $\left.)\right)$. As the TOF of the Ag-based catalysts is structure-independent and size-independent [31], $\Gamma$ should be primarily determined by the number of CASs [47]. Thus, the difference in the reaction rates mainly originates from the number of CASs of $\mathrm{Ag}_{1} / \mathrm{HMO}$, where the number is much higher for Ag-350 than for Ag-150 and Ag-200. Therefore, the top-down strategy can increase the number of CASs, thus improving the catalytic performance.

Catalysts with single-site metal centers are beneficial for investigating reaction mechanisms because of the absence of the electronic quantum size effect [5-7] and structure sensitivity $[8,9]$. Reaction mechanisms, such as the Langmuir-Hinshelwood (L-H) and Eley-Rideal (E-R) models, have often been used to describe catalytic reactions, and, interestingly, the L-H mechanism is more pronounced at low reaction temperatures for supported metal NP catalysts, but the reaction kinetics demonstrate that the $\mathrm{L}-\mathrm{H}$ model cannot describe the predominant reaction mechanism for $\mathrm{HCHO}$ oxidation on Ag-based catalysts [46]. For $\mathrm{Ag}_{1} / \mathrm{HMO}$, the issue becomes simple because $\mathrm{HCHO}$ oxidation on single-site Ag centers cannot occur by a conventional L-H mechanism that requires two adsorption sites.

The E-R mechanism is also not suitable to describe HCHO oxidation on supported metal catalysts through a reaction of adsorbed $\mathrm{HCHO}$ with gaseous $\mathrm{O}_{2}$ owing to an extremely high energy barrier for dissociation of $\mathrm{O}_{2}$. An alternative Mars van Krevelen model is often used to describe high-temperature oxidation reactions over oxide catalysts [48], that is, adsorbed HCHO reacts with lattice oxygen to generate oxygen defects, and $\mathrm{O}_{2}$ then dissociatively adsorbs on the active sites to replenish the oxygen vacant sites to complete the reaction cycle. With this model, there are two critical factors to determine the catalytic activity: oxidation of adsorbed formate (the stable intermediate in $\mathrm{HCHO}$ oxidation) and dissociation of $\mathrm{O}_{2}$ $[18,19,46,49]$, that is, lattice oxygen and molecular oxygen activation, because the activity of lattice oxygen directly governs the oxidation ability of formate.

The activity of the lattice oxygen of the catalysts was investigated by using $\mathrm{H}_{2}$-TPR, and the results are shown in Fig. 8(a). Obviously, the lattice oxygen of $\mathrm{Ag}_{1} / \mathrm{HMO}$ shows a surprisingly high activity at low temperature, which is favorable for the oxidation of adsorbed formate species [18,49]. For $\mathrm{O}_{2}$ activation, Ag $4 d$ orbitals with a partiallly unoccupied state have an open-shell electronic structure [38], which is favorable for improving the catalytic activity, because $\mathrm{O}_{2}$ activation is regarded as an important rate-limiting step [49,50]. The open-shell nature of the Ag electronic structure, caused by the $d$ - $p$ hybridization and the upshift of the $d$ orbitals induced by Ag-O interactions, have been evidenced by the XANES spectra (Fig. 5), and is further confirmed by the $\mathrm{CO}$ pulse experiment at room temperature (Fig. 8(b)). Clearly, CO molecules chemisorb on Ag active sites rather than on the HMO support, consistent with the donating and back-donation bonding between $\mathrm{CO}$ and metal atoms [51-53]. With the assistance of metal atoms, the Mars van Krevelen mechanism is also feasible at low reaction temperatures for oxidation reaction. Therefore, to some extent, the top-down synthesis provides single-site catalysts as an ideal
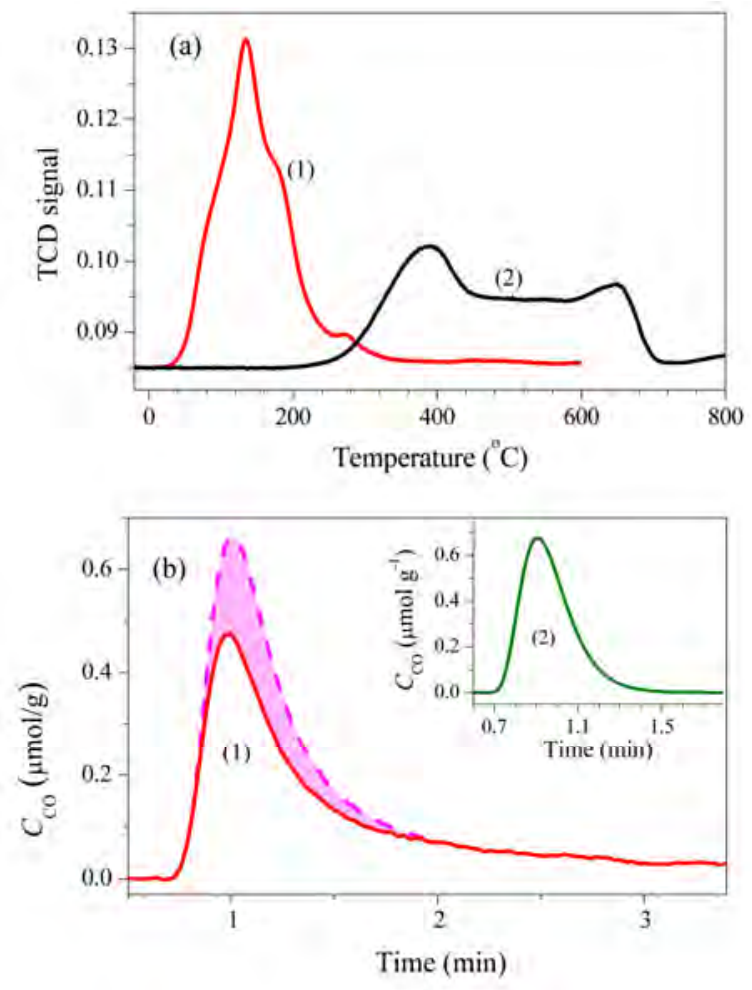

Fig. 8. (a) The $\mathrm{H}_{2}$-TPR profiles of $\mathrm{Ag}_{1} / \mathrm{HMO}$ (1) and $\mathrm{HMO}$ (2); (b) The first CO pulse curves (dark color) and the saturated CO pulse curves (light dash color) of $\mathrm{Ag}_{1} / \mathrm{HMO}$ (1) and HMO (2). The first and saturated CO pulse curves of the HMO support are completely overlapped.

model, which is favorable for investigating complex reaction mechanisms.

\section{Conclusions}

In summary, the synthesis of ADMCs from Ag NPs with the assistance of an HMO support was substantiated through the thermal diffusion process. In situ SXRD, ex situ EXAFTS spectroscopy, and TEM data were used to study the formation of single Ag sites from Ag crystals during the top-down process. Ex situ X-ray absorption spectra were used to study the changes of the geometric and electronic structures of the single metal atoms during this process. The experimental results in conjunction with DFT calculations demonstrate that the driving force of the top-down process is attributed to the electronic perturbation of $\mathrm{Ag}$ frontier orbitals induced by $\mathrm{Ag}-\mathrm{O}$ interactions at the perimeter of the Ag-HMO interface. Two possible functions of the top-down process are proposed by taking the catalytic oxidation of formaldehyde as an example. Therefore, the top-down strategy could assist the design of single-site catalysts that are favorable for studying complex reaction mechanisms of catalytic reactions.

\section{Acknowledgments}

We acknowledge the Shanghai Synchrotron Radiation Facility for the XAS and SXRD measurements. 


\section{Graphical Abstract}

Chin. J. Catal., 2017, 38: 1588-1596 doi: 10.1016/S1872-2067(17)62778-5

Top-down synthesis strategies: Maximum noble-metal atom efficiency in catalytic materials

Yaxin Chen, Zhiwei Huang, Xiao Gu, Zhen Ma, Jianmin Chen, Xingfu Tang *

Fudan University; Congqing University;

Nanjing University of Information Science \& Technology

The top-down strategy is successfully used to synthesize atomically dispersed metal catalysts from supported Ag nanoparticles by a thermal diffusion process. The driving force is attributed to the electronic perturbation of the Ag frontier orbitals.

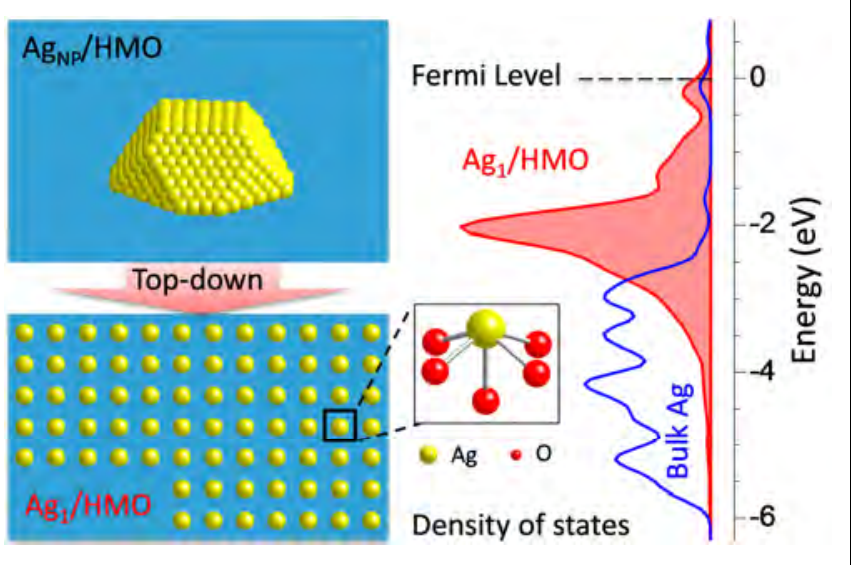

H. F. Garcés, S. L. Suib, Adv. Funct. Mater., 2011, 21, 312-323.

\section{References}

[1] H. S. Taylor, Proc. R. Soc. London, Ser. A, 1925, 108, 105-111.

[2] A. Bruix, J. A. Rodriguez, P. J. Ramírez, S. D. Senanayake, J. Evans, J. B. Park, D. Stacchiola, P. Liu, J. Hrbek, F. Illas, J. Am. Chem. Soc., 2012, 134, 8968-8974.

[3] C. T. Campbell, Nat. Chem., 2012, 4, 597-598.

[4] T. Zambelli, J. Wintterlin, J. Trost, G. Ertl, Science, 1996, 273, 1688-1690.

[5] M. Valden, X. Lai, D. W. Goodman, Science, 1998, 281, 1647-1650.

[6] O. Lopez-Acevedo, K. A. Kacprzak, J. Akola, H. Häkkinen, Nat. Chem., 2010, 2, 329-334.

[7] W. A. de Heer, Rev. Mod. Phys., 1993, 65, 611-676.

[8] S. Dahl, A. Logadottir, R. C. Egeberg, J. H. Larsen, I. Chorkendorff, E. Törnqvist, J. K. Nörskov, Phys. Rev. Lett., 1999, 83, 1814-1817.

[9] J. K. Nörskov, T. Bligaard, B. Hvolbæk, F. Abild-Pedersen, I. Chorkendorff, C. H. Christensen, Chem. Soc. Rev., 2008, 37, 2163-2171.

[10] N. Acerbi, S. C. E. Tsang, G. Jones, S. Golunski, P. Collier, Angew. Chem. Int. Ed., 2013, 52, 7737-7741.

[11] D. Widmann, R. J. Behm, Angew. Chem. Int. Ed., 2011, 50, 10241-10245.

[12] T. Fujitani, I. Nakamura, Angew. Chem. Int. Ed., 2011, 50, 10144-10147.

[13] C. T. Campbell, S. C. Parker, D. E. Starr, Science, 2002, 298, 811-814.

[14] S. R. Challa, A. T. Delariva, T. W. Hansen, S. Helveg, J. Sehested, P. L. Hansen, F. Garzon, A. K. Datye, J. Am. Chem. Soc., 2011, 133, 20672-20675.

[15] J. H. Kwak, J. Hu, D. Mei, C. Yi, D. H. Kim, C. H. F. Peden, L. F. Allard, J. Szanyi, Science, 2009, 325, 1670-1673.

[16] B. T. Qiao, A. Q. Wang, X. F. Yang, L. F. Allard, Z. Jiang, Y. T. Cui, J. Y. Liu, J. Li, T. Zhang, Nat. Chem., 2011, 3, 634-641.

[17] Q. Wang, D. O'Hare, Chem. Rev., 2012, 112, 4124-4155.

[18] Z. W. Huang, X. Gu, Q. Q. Cao, P. P. Hu, J. M. Hao, J. H. Li, X. F. Tang, Angew. Chem. Int. Ed., 2012, 51, 4198-4203.

[19] P. P. Hu, Z. W. Huang, Z. Amghouz, M. Makkee, F. Xu, F. Kapteijn, A. Dikhtiarenko, Y. X. Chen, X. Gu, X. F. Tang, Angew. Chem. Int. Ed., 2014, 53, 3418-3421.

[20] J. A. Farmer, C. T. Campbell, Science, 2010, 329, 933-936.

[21] J. H. Larsen, J. T. Ranney, D. E. Starr, J. E. Musgrove, C. T. Campbell, Phys. Rev. B, 2001, 63, 195410/1-195410/8.

[22] C. K. King'ondu, N. Opembe, C. H. Chen, K. Ngala, H. Huang, A. Iyer,
[23] Y. X. Chen, T. Kasama, Z. W. Huang, P. P. Hu, J. M. Chen, X. Liu, X. F. Tang, Chem. Eur. J., 2015, 21, 17397-17402.

[24] G. Kresse, J. Furthmüller, Phys. Rev. B, 1996, 54, 11169-11186.

[25] G. Kresse, J. Furthmüller, Comput. Mater. Sci., 1996, 6, 15-50.

[26] J. P. Perdew, J. A. Chevary, S. H. Vosko, K. A. Jackson, M. R. Pederson, D. J. Singh, C. Fiolhais, Phys. Rev. B, 1992, 46, 6671-6687.

[27] A. E. Espinal, L. C. Zhang, C. H. Chen, A. Morey, Y. F. Nie, L. Espinal, B. O. Wells, R. Joesten, M. Aindow, S. L. Suib, Nat. Mater., 2010, 9, 54-59.

[28] C. H. Chen, L. Jin, A. E. Espinal, B. T. Firliet, L. P. Xu, M. Aindow, R. Joesten, S. L. Suib, Small, 2010, 6, 988-992.

[29] M. Bowker, Nat. Mater., 2002, 1, 205-206.

[30] F. M. Chang, M. Jansen, Angew. Chem. Int. Ed., 1984, 23, 906-907.

[31] Y. X. Chen, Z. W. Huang, M. J. Zhou, P. P. Hu, C. T. Du, L. D. Kong, J. M. Chen, X. F. Tang, Chem. Commun., 2016, 52, 9996-9999.

[32] A. Bogicevic, J. Strömquist, B. I. Lundqvist, Phys. Rev. Lett., 1998, 81, 637-640.

[33] M. Flytzani-Stephanopoulos, Acc. Chem. Res., 2014, 47, 783-792.

[34] M. Moses-DeBusk, M. Yoon, L. F. Allard, D. R. Mullins, Z. L. Wu, X. F. Yang, G. Veith, G. M. Stocks, C. K. Narula, J. Am. Chem. Soc., 2013, 135, 12634-12645.

[35] J. D. Kistler, N. Chotigkrai, P. Xu, B. Enderle, P. Praserthdam, C. Y. Chen, N. D. Browning, B. C. Gates, Angew. Chem. Int. Ed., 2014, 53, 8904-8907.

[36] J. Lin, A. Q. Wang, B. T. Qiao, X. Y. Liu, X. F. Yang, X. D. Wang, J. X. Liang, J. Li, J. Y. Liu, T. Zhang, J. Am. Chem. Soc., 2013, 135, 15314-15317.

[37] J. Sun, L. B. He, Y. C. Lo, T. Xu, H. C. Bi, L. T. Sun, Z. Zhang, S. X. Mao, J. Li, Nat. Mater., 2014, 13, 1007-1012.

[38] Y. Lei, F. Mehmood, S. Lee, J. Greeley, B. Lee, S. Seifert, R. E. Winans, J. W. Elam, R. J. Meyer, P. C. Redfern, D. Teschner, R. Schlögl, M. J. Pellin, L. A. Curtiss, S. Vajda, Science, 2010, 328, 224-228.

[39] S. Bordiga, E. Groppo, G. Agostini, J. A. van Bokhoven, C. Lamberti, Chem. Rev., 2013, 113, 1736-1850.

[40] S. D. George, P. Brant, E. I. Solomon, J. Am. Chem. Soc., 2005, 127, 667-674.

[41] S. Ji, E. J. Kan, M. H. Whangbo, J. H. Kim, Y. Qiu, M. Matsuda, H. Yoshida, Z. Hiroi, M. A. Green, T. Ziman, S. H. Lee, Phys. Rev. B, 2010, 81, 094421/1-094421/7.

[42] L. H. Tjeng, M. Meinders, J. van Elp, J. Ghijsen, G. A. Sawatzky, R. L. Johnson, Phys. Rev. B, 1990, 41, 3190-3199.

[43] V. Musolino, A. Selloni, R. Car, J. Chem. Phys., 1998, 108, 
5044-5054.

[44] M. Lee, B. G. Heikes, D. J. Jacob, G. Sachse, B. Anderson, J. Geophys. Res., 1997, 102, 1301-1309.

[45] M. Lee, B. G. Heikes, D. J. Jacob, J. Geophys. Res., 1998, 103, 13201-13212.

[46] C. F. Mao, M. A. Vannice, J. Catal., 1995, 154, 230-244.

[47] G. Deo, I. E. Wachs, J. Catal. 1994, 146, 323-334.

[48] P. Mars, D. W. van Krevelen, Chem. Eng. Sci., 1954, 3 (Spec. Suppl.), 41-59.
[49] P. P. Hu, Z. Amghouz, Z. W. Huang, F. Xu, Y. C. Chen, X. F. Tang, Environ. Sci. Technol., 2015, 49, 2384-2390.

[50] F. Xu, Z. W. Huang, P. P. Hu, Y. X. Chen, L. Zheng, J. Y. Gao, X. F. Tang, Chem. Commun., 2015, 51, 9888-9891.

[51] B. Hammer, Y. Morikawa, J. K. Nörskov, Phys. Rev. Lett., 1996, 76, 2141-2144.

[52] J. A. Rodriguez, D. W. Goodman, Science, 1992, 257, 897-903.

[53] Y. X. Chen, Z. W. Huang, P. P. Hu, J. M. Chen, X. F. Tang, Catal. Commun., 2016, 75, 74-77.

\title{
自上向下的合成策略: 最大程度提高贵金属的原子利用率
}

\author{
陈雅欣 ${ }^{\mathrm{a}}$, 黄志伟 ${ }^{\mathrm{a}}$, 顾 晓 ${ }^{\mathrm{b}}$ ，马 榛 ${ }^{\mathrm{a}}$, 陈建民 ${ }^{\mathrm{a}}$, 唐幸福, ${ }^{\mathrm{a}, \mathrm{c}}{ }^{*}$ \\ a复旦大学环境科学与工程系, 大气科学研究院, 上海市大气颗粒物污染与防治重点实验室, 上海200433 \\ b重庆大学应用物理系, 重庆 401331 \\ c南京信息工程大学, 江苏省大气环境与装备协同创新中心, 江苏南京 210044
}

\begin{abstract}
摘要: 因为贵金属的价格比较高, 并且很多催化反应主要发生在载体和金属接触的周围原子, 所以减少贵金属的粒径对于 提高金属原子利用率是非常可取的. 原子利用率的最高极限就是形成单原子催化活性中心, 然而合成稳定的单原子金属 催化剂是一个巨大的挑战, 因为单原子金属极易聚合成较大的金属颗粒. 尽管存在着很大的困难, 合成稳定的单原子金属 还是可能的. 研究表明, 单原子金属容易镶嵌在表面能量最高的活性位上, 以降低金属和载体的总能量, 使之达到最稳定 状态. 随着金属的负载量增加, 以此单原子金属为“晶种”将形成金属纳米粒子. 根据这一原理, 我们通过简单热扩散方法 在HMO表面把 $\mathrm{Ag}$ 纳米粒子“拆分”成单个的Ag原子, 并稳定地镶嵌在由HMO四个氧形成的空穴上(HMO的孔道口), 使体系 的能量降到最低. 我们通过原位X射线衍射(XRD)、扩展X射线吸收精细结构光谱(EXAFS)和电子显微镜照片(TEM)详细证 明了这种自上而下的合成过程, 并通过X射线吸收近边结构光谱(XANES)、氢气程序升温还原 $\left(\mathrm{H}_{2}-\mathrm{TPR}\right) 、 \mathrm{CO}$ 吸附实验等表 征手段和理论计算说明了诱导这一过程的原因.

首先我们合成了具有高比表面积的Hollandite型二氧化锰(HMO)纳米颗粒, 并且在上面负载纳米银颗粒. TEM数据表 明经过焙烧纳米银颗粒消失, 形成单原子分散在 $\mathrm{HMO}$ 表面. 原位XRD的结果表明随着焙烧温度的升高, 银颗粒的衍射峰强 度逐渐降低, 最后消失, 说明纳米银颗粒随着温度的升高逐渐减少, 最后达到银高分散的状态. 通过对 $\mathrm{Ag}(111)$ 衍射峰强度 进行分析, 我们发现当温度低于 $150{ }^{\circ} \mathrm{C}$ 时, $\mathrm{Ag}(111)$ 衍射峰强度基本保持不变, 说明银颗粒没有变化. 当温度高于 $150{ }^{\circ} \mathrm{C}$ 时, $\operatorname{Ag}(111)$ 衍射峰强度开始减小, 并且减小的程度随温度的升高而变大. 当温度高于 $260^{\circ} \mathrm{C}$ 时, $\mathrm{Ag}(111)$ 衍射峰消失. 为了更好 的研究这个过程, 我们分别在 $150,200,350^{\circ} \mathrm{C}$ 焙烧银颗粒的样品, 并测试了它们的EXAFS谱. 结果表明随着焙烧温度的升 高, 银和银之间配位数减小, 意味着银颗粒的减小. $350^{\circ} \mathrm{C}$ 焙烧样品的EXAFS谱在银原子散射的 $0.28-0.30 \mathrm{~nm}$ 范围内没有吸 收峰, 说明银原子在HMO表面高度分散. 然后我们通过XANES谱和理论计算证明了银和载体表面晶格氧的相互作用导致 银的前线轨道的电子重新发生排布, 从而诱导了整个自上向下的合成过程. 最后活性测试表明, 单原子银催化剂在甲醛催 化氧化中表现出最好的催化活性, 并简单研究了单原子催化氧化甲醛的机理. 因此这种合成策略有两个重要的作用: (1)增 加催化活性位的数量; (2)单原子催化剂的合成有利于催化反应机理的研究, 比如甲醛催化氧化.
\end{abstract}

关键词: 自上向下合成; 单原子分散; 催化活性位; 金属-载体相互作用; 甲醛氧化

收稿日期: 2016-11-29. 接受日期: 2016-12-30. 出版日期: 2017-09-05.

*通讯联系人. 电话: (021)65642997; 传真: (021)65643597; 电子信箱: tangxf@fudan.edu.cn 基金来源：国家自然科学基金(21477023); 上海市科学技术委员会基础研究重点项目(14JC1400400).

本文的英文电子版由Elsevier出版社在ScienceDirect上出版(http://www.sciencedirect.com/science/journal/18722067). 